\title{
Measurement of Organizational Culture and Climate in Healthcare
}

\author{
Robyn R.M. Gershon, DrPH, MHS, MT \\ Patricia W. Stone, PbD, RN, MPH \\ Suzanne Bakken, DNSc, RN \\ Elaine Larson, $\mathrm{P} h \mathrm{D}, \mathrm{RN}, \mathrm{CIC}$
}

Although there is increasing interest in the relationship between organizational constructs and health services outcomes, information on the reliability and validity of the instruments measuring these constructs is sparse.

Twelve instruments were identified that may have applicability in measuring organizational constructs in the healthcare setting. The authors describe and characterize these instruments and discuss the implications for nurse administrators.

Although the concepts of organizational culture and organizational climate were first developed in the early 1930 s as part of the human relations movement, they did not become widely known in the healthcare field until the 1980 s, when managed care initiatives resulted in unprecedented industry-wide organizational changes. ${ }^{1,2}$ These initiatives, which included reduced length of hospital stay, capitated payment plans, and managed care systems, led not only to impressive savings in healthcare-related costs but also to widespread reports of employee and patient dissatisfaction. ${ }^{3}$ Healthcare workers, especially nurses, reported high levels of work stress and a perceived decrease in their ability to supervise support staff and/or to provide quality care to patients. ${ }^{46}$ Increasingly, both researchers and front-line

Authors' affiliation: Associate Professor (Dr Gershon), Mailman School of Public Health; Assistant Professor (Dr Stone), Alumni Professor (Dr Bakken), Professor (Dr Larson), School of Nursing, Columbia University, New York, NY.

Corresponding author: Dr Gershon, Columbia University, Mailman School of Public Health, Department of Sociomedical Sciences, 600 West 168th St, 4th Floor, New York, NY 10032 \{rg405@ columbia.edu).

This article was funded, in part, by AHRQ (1R01HS013114) and CDC/NIOSH (520722) and NINR (P20NR07799). workers hypothesized that rapid organizational change was to blame for the deteriorating morale and quality of care. ${ }^{7 \cdot 10}$ By the late 1990 s, numerous and well-documented reports of poor patient care, coupled with well-publicized anecdotal reports of medical errors, heightened the public's concern about the quality of healthcare., ${ }^{211-16}$

In response to these concerns, the Institute of Medicine formed a Quality of Healthcare Committee to develop strategies to improve the overall quality of patient care in the United States. The committee's report on patient safety, To Err is Human, played an important role in focusing the nation's attention on this issue and led, in part, to the creation of a Federal Quality Interagency Coordination Task Force, which included representatives from the Agency for Healthcare Research and Quality (AHRQ). ${ }^{11,16,17}$ This task force cosponsored 2 conferences that highlighted the effect of healthcare working conditions on patient safety and concluded that interventions designed to improve the healthcare workplace would also likely improve the overall quality of healthcare. The specific working conditions identified included: (1) the physical work environment, (2) work hours and staffing levels, and (3) organizational culture and climate. In 2001, the AHRQ funded 21 studies examining these factors as one of the first steps in its patient safety initiative. Fourteen of these studies $(66 \%)$ involve some measure of organizational culture and climate, further emphasizing the need for well-defined, well-characterized, and psychometrically valid measures of organizational constructs for the healthcare setting."

The goal of this review was to identify potentially useful instruments to measure these constructs in healthcare to assist those who wish to design a 
study, assess a proposed study, or evaluate the findings of studies that incorporate these measures. To accomplish this, we conducted a systematic review of the biomedical literature with the following $2 \mathrm{ob}$ jectives: (1) to clarify the definition of organizational culture and climate and to begin the process of standardization of the terminology and (2) to identify instruments that measure the constructs of organizational culture and organizational climate.

\section{Methods}

We developed a strategy for a comprehensive search of the peer-reviewed literature for appropriate instruments published in the English language. Our search strategy included identifying keywords ("organizational culture" and "organizational climate" paired with "occupational health," "medical errors," "quality of care," "safety management," and "outcomes assessment") and searching suitable databases (Medline, HealthStar, CINAHL, and Health and Psychological Instruments).

From this original search, we developed a preliminary list of journal articles that measured organizational culture and climate. Abstracts, where available, were obtained and reviewed. For articles without an available abstract, we obtained and reviewed the article. We made every effort to retrieve a copy of the original instrument, as well as the fulltext version of the article in which the instrument was originally published. If, after extensive efforts, we were still unable to retrieve either the publication or a copy of the instrument, for example, our difficulty in obtaining a copy of the Michigan Organizational Assessment Questionnaire, we concluded that it was not sufficiently accessible to be of general use and eliminated it from further consideration (unpublished data). We then entered the reference for each original instrument into the Science Citation Index (SCI) Expanded (electronic version) and categorized the citations thus identified as either "health services research-related" or "other." Citations placed into the "other" category were eliminated from further consideration.

Next, using a standard report form that we developed, the following information was abstracted: (1) full citation of the original article; (2) the constructs and subconstructs measured; (3) the psychometric properties of the subconstructs and whether psychometric testing was minimal (relying on only one type of reliability and validity test, such as Cronbach's alpha), moderate (which included a reliability and validity test plus additional psychometric testing, such as factor analysis), or extensive (with testing that involved more than 1 sample or study and at least 1 factor analysis); (4) the original target population and purpose of the instrument; (5) the full citation of any articles that referred to the original reference and abstract if available; and (6) a summary of healthcare-related results of studies that used the various instruments. For detailed information on each instrument, including a full summary of the studies' results, please contact the senior author. To reduce bias, 1 person entered the data for each publication and a second person reviewed the completed report form to double-check for accuracy. We limited inclusion in the final list to those instruments (original or modified versions) that met at least minimal psychometric standards and were cited at least once in the healthcare sciences literature.

To understand the similarities and differences among the various instruments and to conceptualize the subconstructs, we carefully reviewed each instrument and generated a nonredundant list of subconstructs identified in the instruments. Each member of the research team independently grouped the subconstructs into major dimensions and then the team as a whole reached consensus on the final categorization of the subconstructs into major dimensions. We also agreed on the terminology they assigned to each dimension. The team then rereviewed each instrument to determine which of the major dimensions each instrument addressed.

\section{Results}

The initial literature search yielded 311 citations; however, most of these were theoretical papers, lacking either instruments and/or data. Only 12 of the original 311 citations described an original organizational instrument and met our inclusion criteria. ${ }^{2.18 .24}$ Table 1 describes all 12 instruments, their total number of citations, the number of healthcare citations, and their dimensions (where available) and subconstructs. These 12 publications were cited 920 times, 202 of which were in the healthcare literature. The original 12 publications spanned approximately 20 years (1968-1989), with most published in the mid-1980s. Most of the citations in the healthcare literature were published in the past 5 years, and virtually all the studies involved nurses, generally hospital-based.

All but 1 instrument (the Work Environment Instrument ${ }^{23}$ ) used a Likert-type scale, ${ }^{19}$ with the number of items in each instrument ranging from 18 to $120 .{ }^{19}$ The psychometric analyses of each 
scale were generally limited, for example, most authors reported only the results of construct validity testing using correlation analysis. Reliability testing was generally not performed or was extremely limited (eg, only internal consistency was measured) as compared to Norbeck's criteria for minimal psychometric properties for reporting of an instrument. ${ }^{29}$ Five $(42 \%)$ of the instruments were developed specifically for use in healthcare, ${ }^{2,19,30-32}$ and 3 were designed to measure organizational culture. ${ }^{21,30,33}$ Two of the instruments, the Organizational Culture Inventory ${ }^{21}$ and the Quality Improvement Implementation Survey, ${ }^{19}$ measured the dimensions rather than the subconstructs of organizational climate (eg, they measured a predetermined "type" of leadership style) and, therefore, were omitted from further subconstruct analysis.

Table 2 displays the major dimensions addressed in each of the instruments and the results of our subconstruct analysis. From the remaining 10 instruments, we identified 116 different subconstructs, which we then categorized into 4 major dimensions: (1) leadership characteristics (eg, leadership styles, such as degree and type of supervision, degree of support and trust, degree of aloofness, and type of leadership hierarchy), (2) group behaviors and relationships (eg, characteristics of interpersonal interactions, group behaviors, perceptions of coworker trust, degree of group supportiveness, group cohesion, and coordination of group effort), (3) communications (eg, formal and informal mechanisms for transfer of information and for conflict resolution), and (4) structural attributes of quality of work life (eg, rewards, working conditions, hours of work, forced overtime, and job security). We also identified the major healthcare-related outcomes, the most common being patient satisfaction, job satisfaction, motivation, work stress, and turnover.

\section{Discussion}

\section{Organizational Culture and Climate Constructs}

There is increasing evidence that aspects of both organizational culture and organizational climate may play key roles regarding organizational outcomes. ${ }^{34,35}$ Within healthcare organizations, these constructs may have important effects on health services-related outcomes, including patient quality of care indicators. ${ }^{36-44}$ Therefore, valid and reliable measures of these constructs are necessary not only for researchers but also for healthcare managers and administrators with responsibilities for health services outcomes. Also, there is a benefit to peri- odically "taking the pulse" of an organization, especially before and after major management changes. ${ }^{45-47}$ Unfortunately, measuring organizational culture and climate can be daunting for several reasons. Probably the most important reason and certainly the most confusing is the tendency for the 2 terms to be used interchangeably. There is also lack of agreement on the definition of these terms, as well as the major dimensions that comprise them. In addition, there is variability on the items used to measure the various dimensions. . $^{33,48-53}$

We noted in our review that although many of the instruments had several dimensions in common (eg, leadership style), the terminology used to describe these differed greatly across instruments. This lack of uniformity in terminology was noted across instruments and in the subsequent healthcare studies as well and is recognized as a source of confusion in the organizational behavior literature in general.$^{34}$ In fact, a recent review noted 54 different definitions for organizational climate alone. ${ }^{54}$ Consistently applied terminology and consistency in the measures used were generally only seen across multiple studies conducted by the same author. ${ }^{18,30,55}$

The lack of uniformity and clarity surrounding these organizational constructs may result, in part, from their multidimensionality (ie, they are a composite of several different yet highly interrelated subconstructs).$^{49}$ There is also difficulty in determining where culture leaves and climate begins, because they so intimately affect and define each other. Yet to measure these constructs properly, they clearly must be defined.

\section{Distinction Between Organizational Culture and Organizational Climate}

Organizational culture has been defined as the norms, values, and basic assumptions of a given organization..$^{56,57}$ This, in turn, is important because it drives both the quality of work life and the quality of care in healthcare organizations. Organizational climate, in comparison, more closely reflects the employees' perception of the organization's culture; for example, it is a collective reflection of their experience of the culture. ${ }^{49}$ Aspects of organizational climate are easier to measure because they are tangible. Such things as policies, procedures, and reward systems are relatively easy to assess. In comparison, culture is relatively difficult to assess because the organizations' values and beliefs are more intangible. Both constructs may be evaluated using qualitative and quantitative methods, although it has been suggested that qualitative methods are better suited to 
Table 1. Organizationd Cuture and Chinate lnstruments.

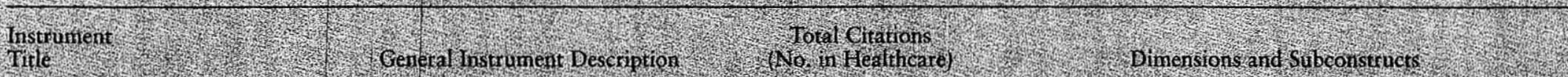

Modified Organizaronat:

Climate Descipitre.

Questronnare?

Organzational Clinate

Questionnaire?

Organizational Elimate Measure

-

Work Bnviontinent Tistrument?

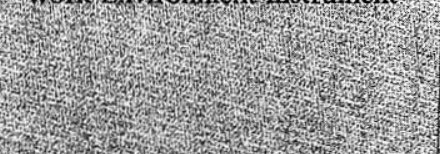

Viofile of Organizational

Charactetistes

Organizational Ellure hdex

Organizational Ouestionnalue?

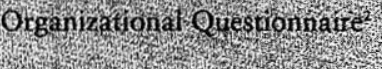

T.

Work dimate sirvey

Nursing Work Index ?

7.

Organizational Gulture

inventotiz

2.

100 Ninse Physician

Questionmaine?

Qualiat Inprovenent

Sing ementation sivivy
28 inemsions 8 subconstructs (64 items)

9 subconstrues ( 50 itens)

11 suponstructs 65 items)

(r.t.

3 dinensions: 10 subconstructs $(90$ tents

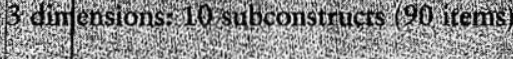

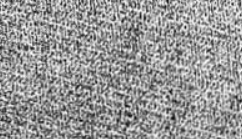

6 sulleonstiacts ( 18 tems)

3. subconstructs (24 trens)

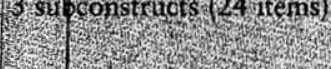

6 subonstucts ( 3 irins)

1.

3. subconstitucts (37 ie ins)

$12 x^{2}-2 x^{2}$

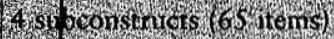

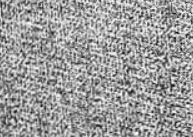

$133(6)$

$254(6)$

1.4 $(2)$

t.t.

$25,(2)$

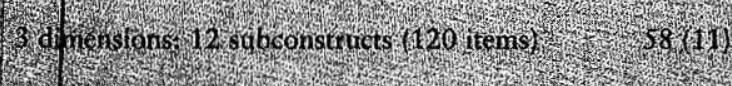

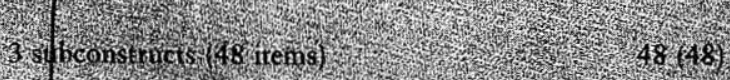

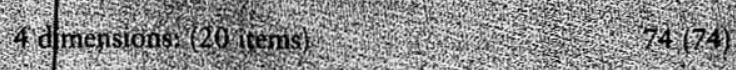

Group behavar espris, 1hinacy, disengagement, hind ance

Leader be bavior thrist motwation, congideration. production emphasis, toofiness

Structure tesponsibility, reward, isk, warn the suppoit standards, conflict, identsy

A uronony y conflict s cooperation, social relations: stiuc ure, level of rewards, performance revard depen dency motivation to achiever status polarization, flexibit. ify and inovation, decision centralization, supportiveness

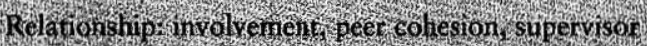
support
Persond growth a wonony, tas orientation, wotk pressure

System namienance and change: clanty, control, in ovation, physical confort

Leadership, morikation, connunicaton, decisions: goals control

Bureaveratic cutures, innovative cullures, sippootive ciltures

Organzational climate of the hospiff tadministration, organizational climare conmunication, supervisoty

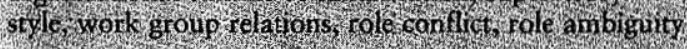

Subo dinates perceptions of wo th climate, work

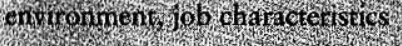

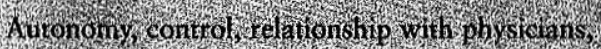
orgenizational sup port

Aggressive-defensive cilture

Oprositional power

Competive-pefectionistic

Tean sarisfacton. peoplesecuinty task securio

Goup culture

De, wopmental culture

Rational cilture

Thier archeal culture: 


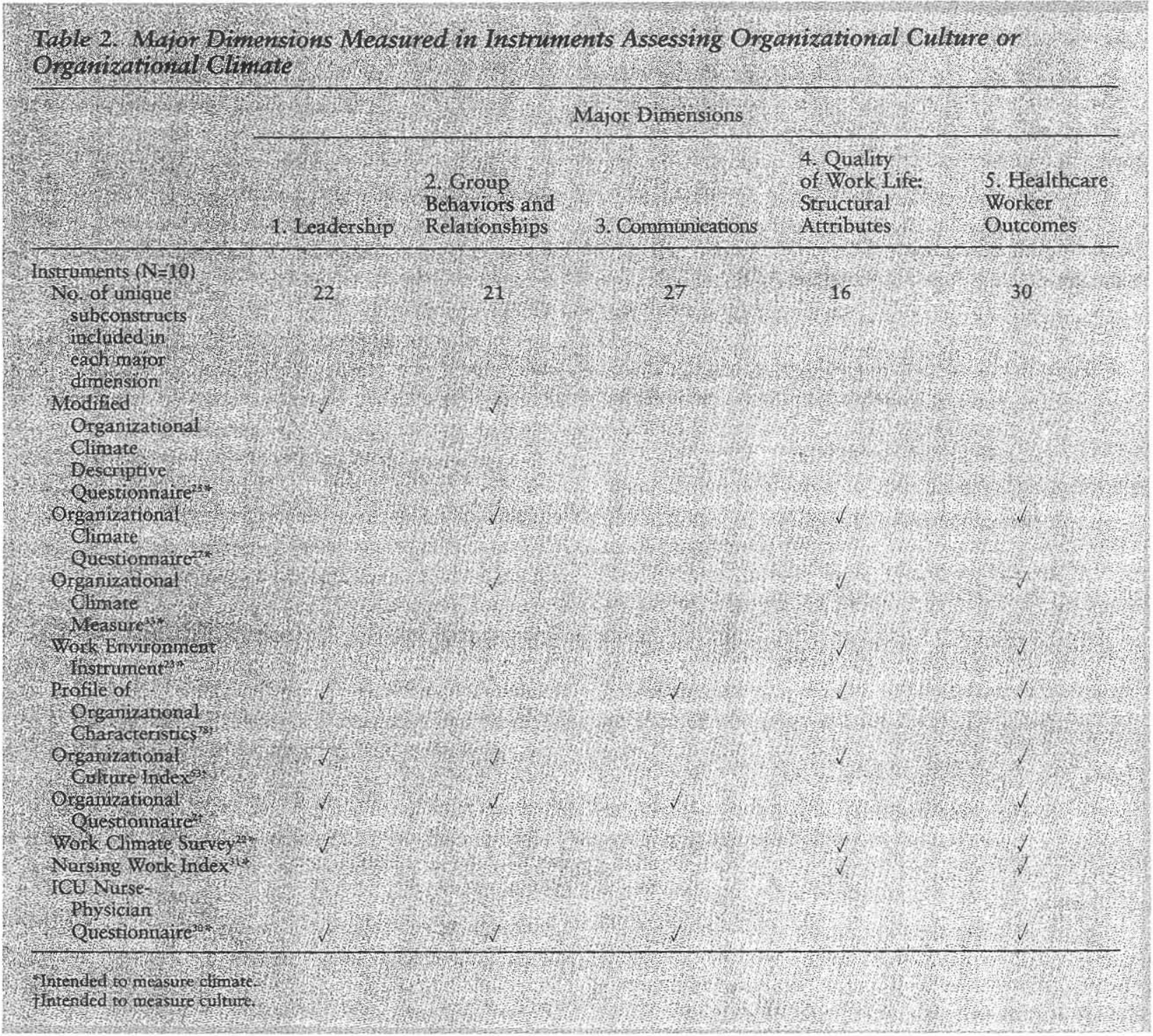

measure culture, with quantitative methods best suited to measure climate. ${ }^{56}$ All 12 instruments that we reviewed provided quantitative measures.

\section{Importance of These Constructs}

Why are organizational culture and climate so important in the healthcare work setting? First, there is increasing evidence that certain aspects of organizational culture (eg, little or no value for individual responsibility or in open and freely flowing communication) and climate (eg, rigid leadership styles and poor communication channels) are associated with lower rates of worker morale, higher levels of work stress, higher accident rates, higher burnout rates, higher turnover, and higher adverse events re- lated to patient quality of care issues. ${ }^{58-67}$ These issues are a key concern for today's nurse administrator or executive.

Second, the more clearly cultural aspects are articulated to employees, the more cohesive and stable the workers collective behavior will be..$^{51,57,68}$ Conversely, if aspects of the organizational culture are ill-defined, frequently shifting, poorly communicated, not reinforced, and/or poorly supported administratively, both the employees' collective perceptions and their behaviors (ie, delivery of care, safe work practices, and teamwork) will be inconsistent. Both nurse executives, who in many instances serve as directors of patient care services, as well as administrators, are well positioned to not only significantly influence organizational culture 
but also to designate strategies for operationalizing that culture (ie, to help form climate).

Third, if an organization wants to send a clear message on any given aspect of its values and principles (eg, patient safety), it is imperative that the organization communicate its beliefs and positions unequivocally. This also allows for a comparison of employees' values and beliefs with those of their work organization, and, if there is a mismatch, termination of employment (initiated by either side) can ensue. In addition, clearly articulated organizational positions help new employees orient themselves and "fit in" and also helps to reinforce group behavior. For example, if an organization makes it evident that patient safety is a high priority, then new and current employees will quickly understand and appreciate what that means in how they deliver patient care. ${ }^{69}$

Therefore, one could argue that to effectively communicate the cultural aspects of an organization, the organization must both communicate and demonstrate its commitment to any particular attribute through both word and deed. If employees are not given the necessary tools to meet organizational expectations (eg, through the provision of adequate staffing) then, regardless of the cultural message espoused, the "real" message will be communicated. That is why it is important to attend to the cultural attributes of an organization, so that the goals the organization is striving for can be achieved.

\section{Conclusions}

To bring some clarity to the issue, we identified several instruments, as well as the dimensions they address, for their potential use in health services. However, as in any literature review, a limitation of the study is that our search strategy may have inadvertently missed some information. A recent review of organizational instruments published by researchers from the United Kingdom included several that our search did not identify. ${ }^{62}$ Our review was also limited by our inability to obtain copies of all of the older original citations and instruments. Additionally, our strategy for categorizing constructs was limited by the potential biases and experience of the research team members. Nevertheless, this review provides some guidance in measuring organizational constructs in the healthcare setting.

\section{Recommendations}

Based on our review, we make the following recommendations for nurse executives and re- searchers: (1) adopt and consistently use uniform terminology; (2) guide all health services organizational studies with a theoretical framework that can be tested; (3) apply standard and psychometrically sound instruments, possessing content, face, criterion, and construct validity; (4) ensure that all measures be as specific and targeted as possible; and (5) apply high-level statistical analysis where feasible, including path analysis and multiple regression to verify the relationship between culture, climate and various outcomes.

Nurse executives or administrators who are evaluating the results of studies of organizational culture and climate must carefully examine the measurements used in the constructs included and the psychometric properties of the instruments. Copies of all subscales are available from the senior author. The nursing executive who is responsible for assessing these issues for their institution can benefit from an increased awareness of the limitations of these measures, as well as their possible use in research studies. In today's competitive climate, hospitals and other healthcare facilities must assess and improve their organizational climate to recruit and retain qualified employees. To assess the effect of initiatives designed to improve the quality of work life, appropriate and well-characterized measures are essential. Therefore, these organizational scales, with their identified subscales, will be helpful to nurse executives who are called on to assess or assist in the evaluation of these constructs. Finally, where possible, it is important to test these measures across different health settings to determine their generalizability and use and to determine if the relationships are similar across settings. We believe that these are essential first steps that should precede any intervention research.

It is important to note that we focused on "global" measures of organizational culture and climate. However, several different subclimates may exist, such as safety climate, patient quality of care climate, workplace fairness and equity climate, and diversity climate. ${ }^{63,70-78}$ Research is thus needed to explore these subclimates in greater detail. Additional research is also clearly needed to determine the relationship among subclimate measures, such as safety climate and global measures of organizational culture and climate and to determine how they may interact to affect various outcome measures. Clearly, we, as health professionals, are embarking on an exciting and challenging journey as we improve our understanding of these complex healthcare organizational constructs. 
Acknowledgments

The authors thank Ms Esther C. Wilson, Ms Toki Dela Cruz, and Ms Melissa Erwin for their admin- istrative assistance on this project. The authors give a special thank you to Dr David DeJoy for his critical review of early drafts of the manuscript.

\section{References}

1. Kreitner R, Kinicki A, eds. Developing people-centered organizations and skills. In: Organizational Behavior. New York: Irwin McGraw-Hill; 2003:31-33.

2. Gray-Toft PA, Anderson JG. Stress among hospital nursing staff: its causes and effects. Soc Sci Med. 1981;15:639-647.

3. Aiken LH, Fagin CM. Evaluating the consequences of hospital restructuring. Med Care. 1997;35(10 suppl):OS1-OS4.

4. Peter D. Hart Research Associates. The Nurse Shortage: Perspectives from Current Direct Care Nurses and Former Direct Care Nurses. Washington, DC: The Federation of Nurses and Health Professionals; 2001.

5. Gershon G, Karkashian C, Walshe E, Vickers D. Workstress Risk Factors Among Hospital-Based Female Health Care Workers. Proceedings of Region III Conference on Injury Prevention. Ellicott City, Md; 1994.

6. Estryn-Behar M, Kaminski M, Peigne E, et al. Stress at work and mental health status among female hospital workers. $\mathrm{Br} J$ Independ Med. 1990;47:20-28.

7. Armstrong-Stassen M, Cameron SJ, Horsburgh ME. The impact of organizational downsizing on the job satisfaction of nurses. Can J Nurs Adm. 1996;9:8-32.

8. Cameron K, Freeman S. Cultural congruence, strength, and type: relationships to effectiveness. Res Organ Change Devel. 1991;5:23-58.

9. Shogren B, Calkins A. Preliminary findings of Minnesota Nurses Association Research Project on Occupational Injury/illness in Minnesota Between 1990-1994. St. Paul, Minn: The Minnesota Nurses Association; 1995.

10. Corrigan PW, Holmes EP, Luchins D, Buican B, Basit A, Parkes J. Staff burnout in a psychiatric hospital: a cross-lagged panel design. J Organ Behau. 1994;15:65-75.

11. Conklin D, MacFarland V, Kinnie-Steeves A, Chenger P. Medication errors by nurses: contributing factors. AARN News Lett. 1990;46:8-9.

12. Eisenberg JM, Bowman CC, Foster NE. Does a healthy health care workplace produce higher-quality care? Joint Commission J Qual Improve. 2001;27:444-457.

13. Kovner $K$. The impact of staffing and organization of work on patient outcomes and health care workers in health care organizations. Joint Commission J Qual Improve. 2001;27:458-468.

14. Wheeler $\mathrm{HH}$. Nurse occupational stress research 5 : sources and determinants of stress. Br J Nurs. 1998;7:40-43.

15. Wunderlich GS, Sloan FA, Davis CK. Nursing Staff in Hospitals and Nursing Homes Is It Adequate? Washington, DC: National Acaderny Press; 1996.

16. Bogner MS. Human error in medicine. Hillsdale, NJ: Erlbaum; 1994.

17. Fact sheet: National health care quality report: Update. Available at: http://www.ahrq.gov/qual/nhqrfact.htm. Accessed October 7, 2002.

18. Shortell SM, Zimmerman JE, Rousseau DM, et al. The performance of intensive care units: does good management make a difference? Med Care. 1994;32:508-525.

19. Quino RE, Kimberly JR. Paradox, planning, and perseverance: guidelines for managerial practice. In: Kimberly JR, Quinn RE, eds. Managing Organizational Transitions. Homewood, Ill: Dow Jones-Richard D. Irwin; 1984:295-313.
20. Kramer M. The magnet hospitals: excellence revisited. $J$ Nurs Adm. 1990;20:35-44.

21. Cooke RA, Lafferty JC. Organizational Culture Inventory: OCI. Plymouth, Mich: Human Synergistics; 1989.

22. Deci EL, Connell JP, Ryan RM. Self-determination in a work organization. J Appl Psychol. 1989;74:580-591.

23. Moos R. Work Enviromment Scale Manual. 2nd ed. Palo Alio, Calif: Consulting Psychologists Press; 1986.

24. Wallach EJ. Individuals and organizations: the cuitural match. Training Devel J. 1983;37:29-36.

25. Halpin AW, Croft DB. The Organizational Climate of Schools. Chicago: Midwest Administration Center, The University of Chicago; 1963.

26. Pritchard RD, Karasick BW. The effects of organizational climate on managerial job performance and job satisfaction. Organ Behav Hum Perform. 1973;9:126-146.

27. Litwin GH, Stringer RA. Motivation and Organizational Climate. Boston: Division of Research, Graduate School of Business Administration, Harvard University Press; 1968.

28. Likert R. A technique for the measurement of attitudes. Arch Psychol. 1932;140:55.

29. Norbeck JS. What constitutes a plausible report of instrument development? Nurs Res. 1985;34:380-382.

30. Shortell SM, Rousseau DM, Gillies RR, Devers KJ, Simons TL. Organizational assessment in intensive care units (ICUs): construct development, reliability, and validity of the ICU nursephysician questionnaire. Med Care. 1991;29:709-726.

31. Kramer M, Hafner LP. Shared values: impact on staff nurse job satisfaction and perceived productivity. Nurs Res. 1989;38:172-177.

32. Likert R. The Human Organization Its Management and Value. New York: McGraw-Hill; 1967.

33. Wallace MJ J5, Ivancevich JM, Lyon HL. Measurement modifcations for assessing organizational climate in hospitals. Acad Manage J. 1975;18:82-97.

34. Ostroff C, Kinicki AJ, Tamkins MM. Organizational culture and climate. In: Borman WC, Ilgen DR, Klimoski RJ, eds. Comprehensive Handbook of Psychology. Vol 12: Industrial and Organizational Psychology. New York: Wiley \& Sons; 2002:565-594.

35. Meeks VL. Organizational culture: origins and weaknesses. Organ Stud. 1988;9:453-473.

36. Needleman J, Buerhaus P, Mattke S, Stewart M, Zelevinsky K. Nurse-staffing levels and the quality of care in hospitals. $N$ Engl $J$ Med. 2002;346:1715-1722.

37. Neat A, Griffin MA, Hart PM. The impact of organizational climete on safety climate and individual behavior. Safety Sci. 2000;34:99-109.

38. Narumi J, Miyazawa S, Miyata H, Suzuki A, Kohsaka S, Kosugi $H$. Analysis of human error in nursing care. Accid Anal Prev. 1999;31:625-629.

39. O'Shea E. Factors contributing to medication errors: a literature review. J Clin Nurs. 1999;8:496-504.

40. Sochalski J, Aiken LH, Fagin CM. Hospital restructuring in the United Scates, Canada, and Western Europe: an outcomes research agenda. Med Care. 1997;35(10 Suppl): OS13OS25. 
41. Vahtera J, Kivimaki M, Pentti J. Effect of organizational downsizing on health of employees. Lancet. 1997;350:1124-1128.

42. Roseman C, Booker JM. Workload and environmental factors in hospital medication errors. Nurs Res. 1995;44:226230.

43. Moses EB, United States, Health Resources and Services Administration, Division of Nursing. The Registered Nurse Population Findings From the National Sample Survey of Registered Nurses, March 1992. Rockville, Md: US Dept of Health and Human Services, Public Health Service, Health Resources and Services Administration; 1992.

44. Milewski R. Impact of peer performance-evaluation on job satisfaction. Am J Hosp Pharmacol. 1983;40:1202-1205.

45. Jones KR, DeBaca V, Yarbrough M. Organizational culture assessment before and after implementing patient-focused care. Nurs Econ. 1997;15:73-80.

46. Knox S, Irving JA. An interactive quality of work life model applied to organizational transition. J Nurs Adm. 1997; 27:39-47.

47. Rantz MJ; Mehr DR, Conn Vf, et at. Assesing quality of nursing home care: the foundation for improving resident outcomes. J Nors Gare Qwal: 1996:10:1-2.

48. Hale AR. Culture's confusions. Safety Sci. 2000;34:1-14.

49. Schneider B, Brief AP, Guzzo RA. Creating a climate and culture for sustainable organizational change. Organ Dynamics. 1996;24:9-11.

50. Shindul-Rothschild J, Duffy M. The impact of restructuring and work design on nursing practice and patient care. Best Pract Benchmarking Healthcare. 1996;1:271-282.

51. Sovie MD. Hospital culture-why create one? Nurs Econ. 1993;11:69-75, 90.

52. Zammuto RF, Krakower JY. Quantitative and qualitative studies of organizational culnure. Res Organ Change Devel. 1991; 5:83-114.

S3. Dastmalchian A, Blyton P, Adamson R. The Climate of Workplace Relations. New York: Routledge; 1991.

54. Verbecke WVMHM. Exploring the conceptual expansion within the field of organizational behavior: organizational climate and organizational culture. J Manage Stud. 1998;35:303329.

55: Shortell SM, O'Brien J, Carman JM, et al. Assessing the impact of continuous quality improvement/total quality management: concept versus implementation. Health Serv Res. 1995; 30:377-401.

56. Hemmelgarn A, Glisson C, Dukes D. Emergency room culture and the emotional support component of Family-Centered Care. Children's Health Care. 2001;30:93-110.

57. Schein EH. Organizational Culture and Leadership. 2nd ed. San Francisco: Jossey-Bass; 1992.

58. Clarke SP, Rockett DM, Sloane DM, Aiken LH. Organizational climate, staffing, and safety equipment as predictors of needlestick injuries and near-misses in hospital nurses. Am J Infect Control. 2002;30:207-216.

59. Dunham-Taylor J. Nurse executive transformational leadership found in participative organizations. J Nurs Adm. 2000; 30:241-250.

60. Gershon RR, Karkashian CD, Grosch JW. Hospital safety climate and its relationship with safe work practices and workplace exposure incidents. Am J Infect Control. 2000;28:211-221.

61. Gershon RRM, Karkashian C, Martin LS, Grosch J, Murphy L. The relationship between safety climate and injury/ exposure in an acure care hospital. American Biological Safety Association. October 15, 1997; La Jolla, Calif.

62. Scott T, Mannion $R$, Davies $H$, Marshall $M$. The quantitative measurement of organizational culture in health care: a review of the available instruments. Health Serv Res. 2003;38:293.

63. Gershon RR, Vlahov D, Felknor SA, et al. Compliance with universal precautions among health care workers at three regional hospitals. Am I Infect Control. 1995;23:225-236.

64. Eastburg M, Williamson M, Gorsuch R, Ridley C. Social support, personality, and burnout in nurses. I Appl Soc Psychol. 1994;24:1233-1250.

65. Fielding J, Weaver SM. A comparison of hospital-and community-based mental health nurses: perceptions of their work environment and psychological health. J Adv Nurs. 1994;19; 1196-1204.

66. Jex SM, Hughes P, Storr C, Baldwin DC, Jr., Conard S, Sheehan DV. Behavioral consequences of job-related stress among resident physicians: the mediating role of psychological strain. Psychol Report. 1991;69:339-349.

67. Gershon R, Karkashian C, Vlahov D, Grimes M, Spannhake E. Correlates of infection control practices in dentistry. Am J Infect Control. 1988;26:29-34.

68. Schein EH. Coñing to a new awareness of organizational culture. Sloan Manage Rev. 1984;25:3-17.

69. Dawis RV. Scale construction. J Counsel Psychol. 1987;34:481489.

70. Dejoy DM, Murphy LR, Gershon RM. Safety climate in health care settings. In: Bitner AC, Champney PC, eds. Advances in Industrial Ergonomics and Safety VII. New York: Taylor \& Francis; 1995.

71. Finn CP. Autonomy: an important component for nurses' job satisfaction. Intl J Nurs Stud. 2001;38:349-357.

72. Wakefieid BJ, Blegen MA, Uden-Holman T, Vaughn $T$, Chrischilles E, Wakefield DS. Organizational culture, continuous quality improvement, and medication administration error reporting. Am J Med Qual. 2001;16:128-134.

73. Wilson MG, Dejoy DM, McGrath AL. Making health care organizations healthy: conceptual model and intervention process. In: dejonge J, Vlerick P, Bussing A, Schaufeli WB, eds. Organizational Psychology and Health Care at the Start of a New Millennium. Mering: Ranier Hampp Verlag; 2001:3-21.

74. Griffin MA, Neal A. Perceptions of safety at work: a framework for linking safety climate to safety performance, knowledge, and motivation. J Occupat Health Psychol. 2000;5:347358.

75. Varonen $U$, Mattila $M$. The safety climate and its relationship to safery practices, safety of the work environment and occupational accidents in eight wood-processing companies. Accid Anal Prev. 2000;32(6):761-769.

76. Zohar D. A group-level model of safety climate: testing the effect of group climate on microaccidents in manufacturing jobs. J Appl Psychol. 2000;85:587-596.

77. Wakefield DS, Wakefield BJ, Uden-Holman T, Borders T, Blegen $\mathrm{M}$, Vaughn $\mathrm{T}$. Understanding why medication administration errors may not be reported. Am J Med Qual. 1999;14:8188.

78. Dejoy DM, Murphy LR, Gershon RM. The influence of employee, job/task, and organizational factors on adherence to Universal Precautions among nurses. Intl J Indust Ergonom. 1995;16:43-S5. 